\title{
Derecho de postulación en Colombia, apoderados judiciales y terminación del poder en el código general del proceso
}

\author{
Right to nomination in Colombia, legal representatives, \\ and termination of power in the general procedural \\ code
}

\section{Carlos Iván Moreno Machado}

Especialista en Responsabilidad Civil y Daño Resarcible Doctorando en "Derecho y Tutela: experiencia contemporánea, comparación y sistema jurídico romanístico" de la Università di Roma II "Tor Vergata" (Italia) y magíster de la misma. Profesor de la Universidad Externado de Colombia Integrante de la Línea de Investigación en Teoría General del Proceso de la Universidad Externado de Colombia. Correo de contacto: carlos.moreno@uexternado.edu.co

\section{Cómo citar este artículo:}

Moreno, C. I. (2022). Derecho de postulación en Colombia, apoderados judiciales y terminación del poder en el código general del proceso. Revista de la Facultad de Derecho y Ciencias Políticas, 52(136), pp. 39-67. doi: https://doi.org/10.18566/rfdcp.v52n136.a03

Recibido: 10 de julio de 2020

Aprobado: 05 de marzo de 2021 


\section{Resumen}

Este artículo abarca la configuración conceptual del derecho de postulación en Colombia, detallando la amplitud de sus excepciones, donde legal y constitucionalmente se autoriza la intervención directa.

Luego de explicar acciones, hipótesis y controversias motivo de excepción; se muestra el esquema de las modalidades del poder en el Código General del Proceso y las vicisitudes de la presentación personal junto con propuestas al respecto; sin olvidar de otro lado, la normatividad para conferir los poderes bajo la emergencia económica, social y ecológica de la pandemia COVID-19. De esta forma, después de emprender un recorrido analítico, se precisa el alcance teórico y la operatividad de los fenómenos de la revocatoria y renuncia del poder, como motivos para la finalización del mismo, a los cuales se agregan, dentro de esta investigación, la muerte del apoderado y dos clases de inhabilidades bautizadas como 'inhabilidad sobrevenida' e 'inhabilidad originaria, las cuales no constituyen causal de nulidad procesal.

La metodología utilizada tuvo por objeto el análisis de normas proferidas antes y después de la Constitución de 1991, de doctrina y de jurisprudencia en las cuales se observan comentarios, críticas y proposiciones, gracias a la simbiosis entre el derecho procesal y el derecho sustancial.

\section{Palabras clave}

Postulación; excepciones; abogado; poder; Covid-19, terminación; inhabilidad.

\section{Abstract}

This article covers the theoretical concept of the right to nomination in Colombia detailing its many exceptions where direct intervention is authorized both legally and constitutionally.

After having explained the legal actions, various hypothesis, and controversies that, in turn, constitute exceptions, the General Code of Procedure's framework and the many vicissitudes of the physical appearance, along with proposals in such regard, are shown without forgetting, on the other hand, the statutes by which powers of attorney are to be produced during the current time (COVID-19).

In this sense, after an adequate analysis, the theoretical reach, as well as the mechanism of action of the revocation of the power of attorney and its renunciation (causes for termination) are laid out. Among the latter, the death of the lawyer representing his or her client and two kinds of legal incompetence known as: «sudden incompetence» (fortuitous) and «original incompetence» (by nature), which do not constitute cause for procedural nullity. 
The methodology by which this article was written had the very intention of analyzing the statutes set forth before and after the 1991 Constitution, and before and after the doctrine (jurists) and case law; statutes in which comments, critics, and propositions are observed due to the existing "symbiosis" between Procedural Law and Positive Law.

\section{Keywords}

Nomination, exceptions, lawyer, power, covid-19, termination, disability

\section{Introducción}

En la dinámica judicial es elemental saber que, en la mayoría de los casos, las partes involucradas en una controversia deben comparecer a los estrados mediante abogados titulados e inscritos. Si bien ello es cierto, es igualmente una realidad que en otras múltiples controversias los titulares de la relación jurídica sustancial que se debate podrán presentarse directamente ante los jueces, lo que implica a todas luces que no requieren de la representación judicial de un abogado. Sin duda, las excepciones a lo que se conoce como derecho de postulación responden a la esencia del interés tutelado, al factor de la cuantía y a la naturaleza del asunto.

Al panorama anterior, se agrega la tesis central de esta investigación que luego de analizar los preceptos normativos respecto del apoderamiento, la postura jurisprudencial y las reflexiones doctrinales, se enfoca en las modalidades de terminación del poder, comentando la operatividad y complejidades de cada una. Para señalar y profundizar que, además, de las causales de culminación del poder en el Código General del Proceso, se observan inhabilidades con las cuales se pueden sancionar al profesional del derecho que contó con autorización para litigar. Observando estos fenómenos que causan vicisitudes al momento de desarrollar las etapas del proceso se plantean unas consecuencias de índole disciplinaria, por un lado, y procesal, por otro lado; con el genuino propósito de que no se vean intrincados los trámites judiciales en los respectivos despachos.

\section{¿Qué es el derecho de postulación o ius postulandi?}

En términos concisos, el derecho de postulación es la prerrogativa jurídica que posee el abogado como profesional del derecho, autorizado por ley y 
habilitado por el órgano que controla la judicatura, para actuar en procesos judiciales o administrativos, pretendiendo o defendiendo intereses ajenos en una causa ajena, es decir, actuando como apoderado de otra persona; o también, en algunos casos, defendiendo intereses que a él le pertenecen, actuando así, en causa propia.

En Colombia, el artículo 229 de la Constitución Política no solamente establece la garantía fundamental de acceso a la administración de justicia o tutela judicial efectiva, sino que, además, consagra el derecho de postulación, al indicar que será la ley la que señalará los casos en que se podrá comparecer ante un juez de la república sin necesidad de abogado.

La norma de rango constitucional indica la existencia de un derecho fundamental (acceso a la administración de justicia), la regla general de un derecho de postulación (necesidad de representación judicial por un abogado) e igualmente deja claro que el legislador podrá indicar las excepciones a la regla general del ius postulandi.

Con un enfoque legal, el derecho de postulación se encuentra consagrado en el artículo 73 del Código General del Proceso, rezando con otras palabras, que es el abogado quien tiene el derecho de postular, lo que se traduce en la aptitud -o incluso en la habilidad estratégica ${ }^{1}$ - de pedir o de pretender (si se trata del ejercicio del derecho de acción); o de excepcionar o contrarrestar una pretensión (si se trata del ejercicio del derecho de contradicción).

Finalmente, como última estocada conceptual, se puede concluir que, por regla general, sin considerar todavía las excepciones, para acceder a la administración de justicia se requiere estar representado por un profesional del derecho, a quien se le llama abogado, el cual debe ser un profesional

1 Uno de los autores italianos más influyentes de la doctrina procesal del siglo XX, CALAMANDREI (1950), enseñó de forma clásica, categórica e inolvidable: "La razón por la cual no basta salir de la Universidad con un grado en procesal civil conseguido con ciento diez y su respectivo elogio, para ser sin duda notados abogados de audiencia, es muy similar, psicológicamente, a aquella razón de común experiencia para la cual no se convierte en hábiles jugadores de ajedrez solamente con el aprendizaje de memoria de un manual que contiene las reglas del tablero de ajedrez. Es verdad que sin conocerlas no se puede jugar: como sin conocer a la perfección las normas del Código de procedimiento no se puede hacer un proceso [...]; pero cuando se conocen las reglas en teoría, lo más importante para aprender el juego es verlas funcionar en práctica, es de experimentar cómo son entendidas y cómo son respetadas por los hombres que deben observarlas". Valiosa enseñanza que no solo se predica para el proceso civil, sino para cualquier tipo de proceso. 
titulado por Universidad, inscrito y autorizado 2 por el Consejo Superior de la Judicatura; pues solo de esta manera, se podrán realizar los actos procesales de parte $^{3}$ que la ley exige para que se tramite un proceso judicial con una representación técnica.

\section{Excepciones a la regla general del derecho de postulación: casos en los que se podrá intervenir en un proceso judicial sin necesidad de abogado}

Respecto de la regla general de intervención en un proceso judicial a través de abogado, existen unas excepciones particulares relacionadas bien sea con la materia de que se trate la controversia o por la cuantía del litigio. Esas excepciones, en las cuales se puede acceder a la administración de justicia sin necesidad de abogado inscrito, es decir, que se puede actuar en causa propia o ajena sin ser abogado inscrito, son las siguientes:

\section{A. Acciones públicas}

Las acciones públicas, son todos aquellos mecanismos que pueden ser ejercidos por cualquier ciudadano para efectos de pretender la protección de sus derechos humanos y fundamentales, para defender sus derechos colectivos, o para ejercer un control público de las actuaciones de las entidades u órganos del Estado, como también de los particulares cuando su comportamiento afecta intereses públicos, es decir, que involucren a toda la comunidad. De ahí el rótulo de "acciones públicas”.

2 Así lo ordena la Ley Estatutaria de Administración de Justicia en el artículo 85 numeral 20. De igual manera, no está de más recordar que con la Ley 1905 de 2018 se exige la aprobación de un examen de Estado para el ejercicio de la profesión de abogado, el cual se aplicará para quienes inicien la carrera de derecho luego del 28 de junio de 2018, tal y como lo dispone el artículo 2 de dicha ley, el cual fue declarado exequible por la Corte Constitucional mediante la Sentencia C-138 de 2019.

3 Por actos procesales de parte, en palabras de COUTURE (2018, p. 167), se entiende "aquellos que el actor y el demandado (y eventualmente el tercero litigante) realizan en el curso del proceso". Esos actos procesales de parte, son por ejemplo, los siguientes: demanda, contestación de la demanda, presentación de demanda de reconvención, contestación de demanda de reconvención, proposición de excepciones previas, adición de la demanda, adición de la demanda de reconvención, reforma de la demanda, reforma de la demanda de reconvención, comparecencia a audiencias, radicación de memoriales, solicitudes de aclaración de providencias, solicitudes de adición de providencias, peticiones varias (de cualquier índole), solicitud de nulidades, iniciación de incidentes, contestación de los incidentes iniciados, interposición de recursos ordinarios y extraordinarios, entre otros. 
Para el análisis de esta excepción establecida en el numeral 1 del artículo 28 del Decreto 196 de 1971, dentro del marco constitucional y legal, como acciones públicas en Colombia, se encuentran las siguientes:

\section{i) Acción de tutela}

La acción de tutela es una acción pública que se interpone para proteger la conculcación de los derechos fundamentales de las personas, bien sea personas naturales o jurídicas. Esta acción se encuentra establecida en el artículo 86 de la Constitución Política. Sin embargo, el hecho de que sea una acción constitucional obliga de igual manera que la misma se interprete de conformidad con los tratados internacionales sobre derechos humanos que han sido ratificados por Colombia.

Al ser una acción que se ventila ante los jueces, mediante ella se materializa el acceso a la administración de justicia sin necesidad de abogado, lo que obliga a cualquier ciudadano a comprender, gracias a la Constitución de 1991, una nueva "práctica judicial" para evitar que se vulneren derechos fundamentales, lo que trae consigo una nueva "relación entre el ciudadano y su Constitución”"

Esta acción la puede interponer cualquier ciudadano, sin necesidad de abogado. No obstante, en aquellos casos en que un ciudadano otorgue poder a un abogado, el poder debe cumplir con todos y cada uno de los requisitos que exige la ley; pues en el caso de que se inicie una acción de tutela y el poder que se allegue no cumpla con los requisitos, entonces esta acción constitucional se deberá inadmitir o decidirla como improcedente, porque quien actúa como representante judicial del accionante no acreditó su calidad de apoderado para ello. De igual manera, es necesario indicar que no es válido para presentar esta acción, el poder que se haya otorgado para tramitar otra acción diferente de la acción de tutela.

\footnotetext{
$4 \quad$ "La acción de tutela, como ninguna otra, propicia el contacto directo del ciudadano con la administración de justicia, en la medida en que no exige la mediación del "letrado" o abogado, como sí acontece con las acciones previstas en los códigos y en las leyes. En este sentido y de acuerdo con el artículo 86 de la Carta, la acción puede ser ejercida por "toda persona", es decir, por menores de edad, por personas con algún grado de discapacidad, por personas jurídicas, por agentes oficiosos, por defensores públicos, representantes de asociaciones, etc. Este rasgo es muy importante, pues además de intentar que la acción le pertenezca más a las personas que a los abogados, propicia modificaciones en la comprensión de la práctica judicial y en la relación entre el ciudadano y su Constitución". QUINCHE RAMÍREZ. (2017, p. 22).
} 
Por otro lado, si se observa el pronunciamiento más reciente de la Sala de Casación Civil de la Corte Suprema de Justicia, la postura de la Sala fue clara en señalar que cuando se trate de derechos fundamentales ajenos, quien asuma la representación de otro, debe acompañar con su escrito de amparo, el poder especial otorgado por el titular del derecho, debido a que es únicamente el poder especial -y no el poder general-, el que lo habilita para actuar representando a otro ${ }^{5}$. No obstante, la Sala reconoce también, que cuando se actúe en calidad de agente oficioso, bastará con alegar esta calidad.

\section{ii) Acción popular}

La acción popular es una acción colectiva en virtud de la cual se protegen los derechos e intereses colectivos vulnerados o amenazados por un particular o por una entidad pública. Es una acción consagrada en la Ley 472 de 1998 , cuyo éxito privilegia a toda la comunidad y no a un individuo en específico, ni a un grupo o clase determinada de sujetos, aspecto que, entre muchos otros, la hace diferente de la acción de grupo.

De conformidad con el artículo 13 de la Ley 472 de 1998, cualquier ciudadano, por estar legitimado para ejercer esta acción popular, podrá interponerla por sí mismo o a través de alguien que actúe en su nombre. En este último caso, si otorga poder para que otro sea su apoderado, dicho poder debe contar con los requisitos que la ley exige, pues de lo contrario, quien dice ser representante de otro no podría ser reconocido como tal, debido a que no acreditó su calidad de apoderado y en tal sentido la acción popular deberá inadmitirse.

La ley se refirió exclusivamente a la facultad que tiene el demandante para actuar por sí mismo, pero nada dijo respecto de si el demandado podía actuar en causa propia o debía necesariamente estar asistido por un abogado. En este caso, se comparte la posición de que, así como el demandante puede actuar por sí mismo, el demandado también puede hacerlo ${ }^{6}$, es decir, ni demandante

5 (Corte Suprema de Justicia, Sala de Casación Civil, Radicado: 11001-22-03-000-2020-01925-01, 2021). En esta decisión se declaró improcedente la acción de tutela interpuesta por la apoderada general del Fondo Nacional del Ahorro "Carlos Lleras Restrepo" contra el Tribunal Arbitral nombrado por el Centro de Conciliación y Arbitraje de la Cámara de Comercio de Bogotá.

6 En este sentido, compartimos la postura del profesor BEJARANO GUZMÁN. (2019, p. 293): "Dado el carácter de acción pública y ciudadana que identifica las acciones populares, quien promueva una de ellas podrá hacerlo por sí mismo sin la intervención de abogado. Por supuesto, ello no puede significar que no esté autorizada la intervención ni la representación de abogado. Si el accionante actúa por sí mismo, el juez debe notificar a la Defensoría del Pueblo el auto admisorio de la demanda, para que si esta lo considera conveniente intervenga en el proceso. Se trata de una citación forzosa pero no una intervención obligatoria, pues la última queda a discreción de la Defensoría. El artículo 
ni demandado están obligados a comparecer en el trámite de la acción popular a través un abogado, esto, teniendo en cuenta el principio de igualdad y de paridad en el trato legal, pues sostener lo contrario sería pisotear principios generales, pero además elementales, del derecho procesal.

\section{iii) Acción de inconstitucionalidad}

La acción pública de inconstitucionalidad es un mecanismo procesal que busca que una norma jurídica de rango inferior al constitucional sea declarada inexequible por ir en contravía de la Constitución Política, y así, de forma consecuencial, tal disposición sea expulsada del ordenamiento jurídico.

Esta acción de inconstitucionalidad la puede presentar cualquier ciudadano, sea por sí mismo o a través de alguien que actúe como su apoderado o en su nombre. En este último caso, si otorga poder para que otro sea su apoderado, dicho poder debe igualmente contar con los requisitos que la ley exige, pues de lo contrario, quien dice ser representante de otro no podría ser reconocido como tal, debido a que no acreditó su calidad de apoderado y en tal sentido la acción de inconstitucionalidad deberá inadmitirse.

\section{iv) Acción de cumplimiento}

La acción de cumplimiento se halla consagrada en el artículo 87 de la Constitución Política y en las leyes 393 de 1997 y 388 de 1997, a través de ella, cualquier particular o inclusive un servidor público, le solicita a la autoridad jurisdiccional la realización de una actuación o el cumplimiento inmediato de un deber que emana de una ley o de un acto administrativo. Este deber de cumplir la ley o un acto administrativo, puede estar a cargo de una autoridad pública o de un particular que cumpla funciones públicas, de manera que uno de estos, o ambos, serán los sujetos legitimados por pasiva.

\section{B. El Ejercicio del derecho de petición}

Es necesario enseñar de entrada que, el ejercicio del derecho de petición no germina una acción judicial, sino, que su ejercicio implica dos aspectos trascendentales: i) la materialización de un derecho fundamental contemplado

\footnotetext{
13 de la ley solamente se refirió a los demandantes como facultados para actuar por sí mismos, pues nada indicó respecto de quienes sean demandados. En el sentir de los autores, igual prerrogativa tienen los demandados, así la ley nada haya dicho al respecto, porque de lo contrario ello significaría un desequilibrio entre las partes, lesivo del principio de la igualdad de las partes en el proceso".
} 
en el artículo 23 de la Constitución Política, el cual debe garantizarse y respetarse con la respuesta oportuna que se debe dar al peticionario siguiendo el derrotero contemplado en la Ley 1755 de 2015; y ii) la iniciación de una actuación administrativa.

El hecho de que en el numeral 1 del artículo 28 del Decreto 196 de 1971 se indique que cuando se trate del derecho de petición se podrá litigar en causa propia, es un error en la comprensión de este derecho fundamental y de esta modalidad de actuación administrativa, para la cual, y en eso sí acierta el Decreto, no es necesario actuar mediante abogado inscrito.

\section{Procesos de mínima cuantía}

El numeral 2 del artículo 28 del Decreto 196 de 1971 dispone que en aquellos procesos de mínima cuantía se podrá litigar en causa propia y sin necesidad de abogado inscrito.

Los procesos de mínima cuantía, hoy, bajo el Código General del Proceso (art. 25), son aquellos que "versen sobre pretensiones patrimoniales que no excedan el equivalente a cuarenta salarios mínimos legales mensuales vigentes (40 smlmv)".

Estos procesos se tramitan ante el juez civil municipal en única instancia siguiendo el tenor del numeral 1 del artículo 17 del Código General del Proceso.

Esta excepción también aplica para los procesos de mínima cuantía que se instauran y se desarrollan ante algunas autoridades administrativas que cumplen funciones jurisdiccionales según el artículo 24 del Código General del Proceso y las demás normas especiales, siempre y cuando su competencia se determine por el factor cuantía.

El punto a descifrar está relacionado con un proceso que se encuentre dentro de esta excepción o cualquiera de las otras y se haya conferido poder a un abogado a pesar de que no se requería actuar mediante este, y la parte poderdante considere que ya no necesita de su apoderado y desea intervenir directamente. En tal caso, considero que la parte puede intervenir directamente tal y como lo permite la ley, siempre y cuando haya revocado poder a su apoderado o que este haya renunciado, o que, por alguna otra razón, dicho apoderamiento haya terminado, como se verá más adelante. 


\section{Diligencias administrativas de conciliación}

Otra de las excepciones donde no se requiere estar representado por un abogado inscrito, es en el caso de los trámites de conciliación prejudicial o extrajudicial, que como bien se sabe, no son un trámite judicial, sino un trámite de carácter administrativo que de conformidad con la Ley 640 de 2001, la mayoría de las veces constituyen un requisito de procedibilidad para acudir a la administración de justicia. Sí, se reitera la mayoría de las veces, porque en ocasiones, a pesar de existir un proceso judicial en curso, se solicita la conciliación extrajudicial para que las partes puedan conciliar y se produzca la terminación anormal del proceso. En esta hipótesis, para tal trámite extra proceso, tampoco es necesario estar representado por un abogado.

La razón de esta excepción se encuentra en el hecho de que en estas diligencias las partes plenamente capaces analizarán si llegan a un acuerdo conciliatorio (parcial o total) o si por el contrario no están dispuestas a conciliar. Quienes concilian son las partes y no sus abogados, a menos de que estos tengan facultad para ello; pero en todo caso, los efectos recaen sobre las partes y no sobre el profesional que las representa.

\section{E. Procesos de única instancia en materia laboral}

En el mentado numeral 3 del artículo 28 del Decreto 196 de 1971, se encuentra contemplada otra excepción que permite la intervención directa sin necesidad de abogado inscrito, la cual está relacionada con los procesos laborales de única instancia.

Estos procesos que hacen parte de la excepción son todos aquellos procesos que se ventilan ante los jueces municipales de pequeñas causas y competencia múltiple o juzgados municipales de pequeñas causas laborales "cuya cuantía no exceda del equivalente a veinte (20) veces el salario mínimo legal mensual vigente”, tal y como lo señala el inciso 3 del artículo 12 del Código Procesal del Trabajo y de la Seguridad Social.

También, siguiendo el mismo artículo 12 del Código Procesal del Trabajo y de la Seguridad Social, hacen parte de esta excepción todos aquellos procesos que se ventilen ante el juez laboral de circuito en única instancia. De ahí que la exigencia de actuar mediante un abogado inscrito sea específicamente para los procesos laborales que surtan en primera y en segunda instancia. 
Lo anterior queda reafirmado con el artículo 33 del Código Procesal del Trabajo y de la Seguridad Social que señala que:

Para litigar en causa propia o ajena se requerirá ser abogado inscrito, salvo las excepciones de que trata la ley 69 de 1945. Las partes podrán actuar por sí mismas, sin intervención de abogados, en procesos de única instancia y en las audiencias de conciliación.

Con la precisión de que la Ley 69 de 1945 fue derogada expresamente por el artículo 92 del Decreto 196 de 1971.

\section{F. Actos de oposición en diligencias judiciales o administrativas}

Los actos de oposición en las diligencias judiciales 0 administrativas, según lo señala el numeral 4 del artículo 28 del Decreto 196 de 1971, también se encuentran cobijados por la excepción a la regla general del derecho de postulación, lo que trae como consecuencia que tratándose de estas diligencias también se pueda litigar en causa propia. Esta excepción cobija, por ejemplo, diligencias de secuestro, diligencias de entrega o seguridad de bienes, posesión de minas u otras diligencias similares.

Para aterrizar lo anterior, me refiero, por ejemplo, al Código General del Proceso, en sus artículos 308 y 309, los cuales hacen alusión a la entrega de bienes y a la oposición a la entrega, respectivamente. Pongamos el ejemplo donde Pedro debe a Juan la suma de mil millones de pesos $(\$ 1.000 .000 .000)$ para lo cual suscribió una letra de cambio. Llegado el plazo sin que Pedro haya pagado la deuda, Juan decide iniciar un proceso ejecutivo en su contra, en el cual se profiere auto de mandamiento de pago, se profiere también auto que decreta la medida cautelar de embargo sobre un inmueble del demandado; luego de notificado el mandamiento de pago el demandado no propone excepciones, luego se expide auto que ordena seguir adelante con la ejecución y ulteriormente se profiere auto que fija fecha y hora para la diligencia de secuestro; $y$ en esta diligencia de entrega del bien inmueble al secuestre, se opone un tercero ajeno al proceso, alegando ser poseedor y presenta las pruebas sumarias que acreditan tal calidad como lo ordena el numeral 2 del artículo 309 del Código General del Proceso.

Continuando con el ejemplo, de ser admitida la oposición que presentó el tercer poseedor, si quien solicitó la entrega insiste en esta, tanto el solicitante de la entrega como el opositor, dentro de los cinco (5) días siguientes podrán solicitar pruebas que se relacionen con la oposición y vencido este término, 
el juez convocará a audiencia en la que practicará dichas pruebas y resolverá sobre el asunto. Nótese que de conformidad con el numeral 6 del artículo 306 del Código General del Proceso, en esta actuación posterior la ley no exige que el opositor actúe a través de apoderado judicial, por lo tanto, le está vedado al juez exigirle al opositor que confiera poder a un abogado inscrito.

No obstante lo anterior, también merece comentario la hipótesis en la cual el poseedor no haya estado presente en la diligencia de secuestro. En este evento, el numeral 8 del artículo 597 del Código General del Proceso le permite al poseedor que no estuvo presente en la diligencia, que dentro de los veinte (20) días hábiles siguientes a la práctica de la diligencia, solicite al juez que se declare, que aquel tenía la posesión material del bien en el momento en que se practicó la diligencia. En este caso la solicitud se tramitará como incidente y dentro de este el solicitante deberá probar la posesión. Adicionalmente, esta solicitud también la podrá presentar el poseedor que estuvo presente en la diligencia sin apoderado judicial, pero con la salvedad, que, en este último caso, como se encontró presente en la diligencia sin la representación de un abogado, el término para promover el incidente será de cinco (5) días -tal y como se indicó en el párrafo anterior- y no de veinte (20) días.

La advertencia en estos casos está, en que, si bien en estas diligencias se puede litigar en causa propia, aún sin que se tenga en cuenta la cuantía del proceso, en la actuación posterior a las mismas y si la ley señala que se debe actuar mediante abogado inscrito -léase bien, si la ley lo señala-, entonces se deberá intervenir bajo la representación de este, pues es claro que una es la diligencia o el acto de oposición, y otra muy diferente es el proceso donde la misma se realizó.

\section{G. Asuntos que conocen los funcionarios de policía, que se ventilen en municipios que no sean cabecera de circuito y en donde no ejerzan habitualmente por lo menos dos (2) abogados inscritos}

Una excepción que ha pasado desapercibida en el derecho procesal civil, pero no en el derecho policivo, es la relacionada con las controversias o asuntos que conocen los funcionarios de policía. Esta excepción que permite litigar en causa propia o ajena, sin necesidad de abogado inscrito, se encuentra consagrada en el numeral 1 del artículo 29 del Decreto 196 de 1971. 
En los asuntos que conocen los funcionarios de policía (Ley 1801, 2016, art. 205 a 207); no importa si se trata de una única, primera o segunda instancia, se puede intervenir sin necesidad de estar representado por abogado inscrito, siempre y cuando, reiterado, se ventilen en municipios que no sean cabecera de circuito o de distrito judicial y que en el lugar no ejerzan habitualmente por lo menos dos (2) abogados inscritos; y esta última circunstancia la declarará el funcionario o dejará constancia de ella, en el auto que admite la personería para actuar; recordando de todas maneras que la palabra "habitual" se interpreta en el sentido de que en el municipio de manera frecuente y permanente no ejercen dos abogados inscritos; siendo lo habitual algo no relacionado con una temporada específica del año, sino algo que se refiere al diario ejercicio de la profesión en el respectivo municipio.

\section{H. En la primera instancia en los procesos de menor cuantía que se ventilen en municipios que no sean cabecera de circuito y en donde no ejerzan habitualmente por lo menos dos (2) abogados inscritos}

Otra excepción a la regla general de concurrir a la administración de justicia mediante abogado inscrito, es aquella relacionada con los procesos de menor cuantía (superiores a los 40 smlmv pero que no exceden los $150 \mathrm{smlmv}$ ), que se instauren y se tramiten en los municipios que no sean cabecera de circuito o de distrito, es decir, municipios donde no existan jueces civiles de circuito y en los cuales no ejerzan habitualmente dos (2) abogados inscritos. Sobre esto último, reiterado, se trata de una circunstancia que declarará el juez en el auto que admite la personería para actuar.

Esta excepción solo está encaminada a procesos de menor cuantía en primera instancia; de ahí que, si en dicho proceso de menor cuantía se desata una segunda instancia, o si se trata de un proceso de mayor cuantía, la excepción no aplique y por tal razón, se deba actuar mediante un abogado inscrito.

\section{Procesos en los que pueden litigar los estudiantes pertenecientes a los consultorios jurídicos de las facultades de derecho}

Una excepción de gran importancia está vinculada con el servicio social que prestan los estudiantes de los Consultorios Jurídicos a las personas de 
estratos inferiores. En este caso, la exigencia de actuar mediante abogado inscrito se sustituye por la actuación de una persona no graduada, es decir, por la actuación de un estudiante inscrito al Consultorio Jurídico de una Facultad de Derecho y acreditado por aquel.

Se agrega que, estos estudiantes no se encuentran desorientados o solitarios para ejercer esta función (que además es un requisito obligatorio para optar por el grado), sino que, están bajo la supervisión, coordinación y dirección de profesores contratados y designados para ello, bajo las directrices del Consultorio Jurídico, de la Facultad de Derecho y de la Rectoría de la Universidad. De manera que los estudiantes actúan bajo los lineamientos de estos profesores que los orientan, apoyan y ayudan en la elaboración y redacción de memoriales, los instruyen en la preparación de audiencias y los guían para que ellos se desempeñen en las mismas; esto genera la confianza de que el servicio que prestan los estudiantes es de calidad.

Esos procesos en los que pueden actuar dichos estudiantes, de conformidad con el artículo 30 del Decreto 196 de 1971 (modificado por el artículo 1 de la Ley 583 de 2000), son los siguientes: i) procesos penales de que conocen los jueces municipales y los fiscales delegados antes estos, así como ante las autoridades de policía, en condición de apoderados de los implicados; ii) procesos penales de competencia de la jurisdicción ordinaria, como representantes de la parte civil; iii) procesos penales como voceros o defensores en audiencia; iv) procesos laborales, en que la cuantía de la pretensión no exceda de veinte 20 salarios mínimos legales mensuales vigentes y en las diligencias administrativas de conciliación en materia laboral; v) procesos civiles de que conocen los jueces civiles municipales en única instancia; vi) procesos de alimentos que se adelanten ante los jueces de familia; vii) de oficio, en los procesos disciplinarios de competencia de las personerías municipales y Procuraduría General de la Nación; viii) de oficio, en los procesos de responsabilidad fiscal de competencia de las contralorías municipales, distritales, departamentales y general de la república; ix) de oficio, en los procesos administrativos de carácter sancionatorio que adelanten las autoridades administrativas, los organismos de control y las entidades constitucionales autónomas.

Para desarrollar esta función, los estudiantes deben adjuntar a las actuaciones judiciales y/o administrativas, la correspondiente acreditación 0 certificación expedida por el respectivo Consultorio Jurídico de la Facultad de Derecho. 
A título de colofón es menester indicar que, a partir del 1 de julio de 2013, la aprobación para la constitución de los Consultorios Jurídicos corresponde a la Sala Administrativa del Consejo Superior de la Judicatura, como lo establece el numeral 5 del artículo 627 del Código General del Proceso; lo que indica que este trámite ya no es competencia del Tribunal Superior de Distrito Judicial del lugar donde se encuentre el Consultorio Jurídico como lo señaló el artículo 1 de la Ley 583 de 2000.

\section{J. Procesos en los que pueden litigar quienes hayan terminado y aprobado los estudios reglamentarios de derecho en universidad oficialmente reconocida}

La última excepción está relacionada con los procesos en los cuales pueden litigar los que hayan terminado y aprobado los estudios reglamentarios de la carrera de derecho en una universidad oficialmente reconocida, esto es, que se encuentre avalada por el Ministerio de Educación para prestar el servicio público de educación profesional en derecho.

En efecto, quienes no han obtenido el grado o título universitario como profesionales del derecho, si terminaron y aprobaron sus estudios ${ }^{7}$, pueden ejercer como abogados, aunque no hayan obtenido dicho título. Este ejercicio temporal de la profesión de abogado se podrá llevar a cabo exclusivamente por el término de dos (2) años, los cuales son improrrogables y cuyo conteo comienza a partir de la fecha de terminación de estudios; es decir, que si la terminación y aprobación de materias tiene fecha del día 10 de diciembre de 2020; entonces la licencia temporal le permitirá litigar al solicitante hasta el 10 de diciembre de 2022.

Terminar y aprobar los estudios significa haber agotado el pénsum de la carrera de derecho con la superación positiva de todos los exámenes y haber aprobado el Consultorio Jurídico. Vale resaltar que los preparatorios no constituyen parte del plan de estudios de la carrera, sino un requisito final para optar por el título profesional; de ahí la razón por la cual el estudiante que haya terminado y aprobado todas las materias del pénsum, pero no haya realizado preparatorios, pueda, y en efecto así sucede en la práctica, solicitar la licencia temporal de abogado.

$\overline{7}$ "[...] de modo que quien terminó sus estudios, pero aún no los aprobó, verá reducida su posibilidad de litigar con base en lo dispuesto en el precepto comentado. Es congruente esta disposición por cuanto en cierta manera se sanciona así al estudiante descuidado o negligente" LÓPEZ BLANCO (2017, p.407). 
Esta licencia temporal de abogado, siguiendo el numeral 5 del artículo 627 del Código General del Proceso, será expedida por la Sala Administrativa del Consejo Superior de la Judicatura; y una vez esta se obtenga, el abogado temporal podrá actuar como apoderado en los siguientes procesos: i) en la instrucción criminal y en los procesos penales, civiles y laborales que conozcan en primera o única instancia los jueces municipales o laborales, en segunda, los de circuito y, en ambas instancias, en los de competencia de los jueces de distrito penal aduanero (lo que excluye la posibilidad de pleitear ante los Tribunales Superiores de Distrito Judicial y ante las altas cortes); ii) de oficio, como apoderado o defensor en los procesos penales en general, salvo para sustentar el recurso de casación (lo que reitera el impedimento de que pueda litigar ante la Corte Suprema de Justicia); iii) en las actuaciones y procesos que se surtan ante los funcionarios de policía.

\section{¿Cómo se otorga el apoderamiento judicial?}

Antes que nada, se debe comprender qué significa o qué se entiende por contrato de mandato, pues este contrato precede al acto de apoderamiento, en otras palabras, es el contrato de mandato el que origina la relación jurídico sustancial entre el cliente y el defensor judicial, esto es, antes de la representación judicial (salvo en los casos de apoderados de oficio) primero se celebra el contrato de mandato, luego se instrumentaliza el poder y finalmente se desarrolla la representación dentro del proceso judicial.

El contrato de mandato es un negocio jurídico en virtud del cual un sujeto denominado "mandante" confía a otro denominado "mandatario" la gestión de uno o más negocios, siendo el mandatario un sujeto que actúa por cuenta y riesgo del mandante (Código Civil, art. 2142). En el mandato judicial, donde el mandante es el cliente y el mandatario es el abogado, la obligación de este último es aplicar todo su conocimiento y toda su diligencia para la obtención del éxito en su gestión, asumiendo el profesional del derecho una obligación de medio y no de resultado.

Pasando al apoderamiento ${ }^{8}$ judicial, este es un acto unilateral del poderdante (cliente), el cual, puede ser aceptado o no por el abogado. En caso de que el

$8 \quad$ "El representante, cualquiera que sea la índole de la representación, es tal en cuanto se encuentra investido de una autorización o facultad para obrar por cuenta de otro, y más, a nombre de otro, en este caso con efectos inmediatos y directos sobre el patrimonio del otro sujeto. Investidura que genéricamente se llama poder, término con el cual se indica la correspondiente atribución, procura o acto de apoderamiento en la representación voluntaria": (HINESTROSA, 2008, p. 204). 
abogado acepte, quedará autorizado para actuar en nombre y representación del poderdante. Este apoderamiento judicial se puede conferir mediante dos (2) clases de poder, el general o el especial (Código General del Proceso, art. 74).

\section{A. Poder general}

El poder general es aquel que se confiere mediante escritura pública ante notario. Este poder tiene la particularidad de que faculta al apoderado para representar a su poderdante en toda clase de procesos; lo que cierra de tajo la posibilidad de que se pueda otorgar poder general mediante documento privado.

\section{B. Poder especial}

El poder especial se confiere para uno o varios procesos. Estos procesos o asuntos indicados en el poder deben estar determinados (por ejemplo, indicar el proceso que se trata), y claramente identificados (por ejemplo, señalar con nitidez las partes o sujetos involucradas).

El poder especial se podrá conferir mediante documento privado, mediante mensaje de datos con firma digital, o también, de forma verbal en audiencia o diligencia ante el juez de conocimiento. Sin embargo, nada impide que este poder se confiera mediante escritura pública, siendo esta formalidad innecesaria que, sin duda, aumentaría los costos para dicho fin si se compara con los costos del documento privado con presentación personal ante el notario, o incluso, si se compara con la gratuidad del documento privado con presentación personal ante el juez u la oficina judicial de apoyo. Respecto de los poderes en el exterior, estos se podrán extender ante el cónsul colombiano $o$ ante el funcionario que la ley local autorice.

Se observa, además, que bajo el Código General del Proceso se permite otorgar poder no solo al abogado persona natural, sino también a la persona jurídica cuyo objeto social sea la prestación de servicios jurídicos, y en este caso podrá actuar como profesional cualquiera de los abogados que se encuentre inscrito en el certificado de existencia y representación legal; y como bien se sabe, siempre que no esté expresamente prohibido se puede sustituir poder. De igual forma, cuando se trata de poder conferido a personas jurídicas, estas también pueden sustituir poder a otros abogados que no pertenezcan a dicha firma. En otras palabras, la posibilidad de sustituir poder tratándose 
de personas jurídicas no se encuentra restringida, salvo que el poderdante lo prohíba; prohibición que también se podrá predicar para los poderes otorgados a abogados personas naturales; recordando, que en caso de que se autorice la sustitución de poder y esta se efectúe, tal documento de sustitución se presume auténtico (Código General del Proceso, inc. 2 art. 74; inc. 3 art. 244).

Ahora, si bien el artículo 75 del Código General del Proceso permite otorgar poder a uno o varios abogados; lo cierto es que en ningún caso podrán actuar simultáneamente más de un (1) apoderado judicial. Lo que si se permite es, por ejemplo, otorgar poder a un abogado para que presente la demanda, otorgar poder a otro abogado para que asista a la audiencia inicial, otorgar poder a otro abogado para que practique las pruebas testimoniales, otorgar poder a otro abogado para que practique el interrogatorio al perito que rindió el dictamen, otorgar poder a otro apoderado para que exponga los alegatos de conclusión, otorgar poder a otro abogado para que sustente el recurso de apelación, etc.

\section{i) Presentación personal del poder especial por cuenta del poderdante}

La presentación personal es uno de los aspectos dentro del apoderamiento que más controversias ha generado; por tal motivo, el inciso 2 del artículo 74 del Código General del Proceso, dispone que la presentación personal del poder especial la debe realizar el poderdante y no el apoderado ${ }^{9}$. Previsión legislativa que pone de presente que es únicamente el poderdante el llamado a acudir ante el notario, ante el juez, o ante la oficina judicial de apoyo, para que exhiba su documento de identificación y de esta manera, el funcionario encargado pueda constatar que quien otorga el poder es la persona que identifica como tal.

No obstante lo anterior, en la práctica judicial, debido a la posición de la Sala de Casación Civil de la Corte Suprema de Justicia (Auto del 3 de junio de 1999), el apoderado está llamado a realizar la presentación personal del poder.

\footnotetext{
9 "Obsérvese que el requisito de la obligatoria presentación personal es para el poderdante no para el abogado. Empero, debido a una infortunada interpretación de la Corte se tiene que como consecuencia de su aplicación, se recomienda por razones prácticas, que el abogado, al aceptar el poder, lo que es usual hacerlo en el mismo escrito al suscribirlo en señal de aceptación, autentique su firma, cuidándose de que se tome nota de la existencia de su tarjeta profesional" (LÓPEZ BLANCO, p. 411). El autor tilda de infortunada la interpretación de la Sala de Casación Civil de la Corte Suprema de Justicia, ante lo cual debemos precisar, que no hay una interpretación infortunada, sino una interpretación encaminada a que se verifique que quien actúa como apoderado es profesional del derecho y esté autorizado para litigar; lógicamente, no por una interpretación de esta índole los jueces o magistrados pueden incurrir en extremos que impidan el acceso a la administración de justicia.
} 
ii) Presentación personal del poder especial por cuenta del apoderado: posición de la sala de casación civil de la corte suprema de justicia y la postura adoptada en este artículo

Si bien el inciso 2 del artículo 74 del Código General del Proceso no establece la presentación personal por cuenta del apoderado judicial, exigírsela no es una interpretación contra legem, sino una interpretación que bebe de la fuente normativa del artículo 22 del Decreto 196 de 1971, que se preocupa por asegurar la transparente y verdadera calidad de apoderado judicial del profesional que obra como mandatario judicial. Esa exigencia nace de la interpretación de la Corte Suprema de Justicia, en su Sala de Casación Civil, mediante auto proferido el día 3 de junio de 1999 M.P.: Jose Fernando Ramírez Gómez, Expediente: 7657, cuando se refirió al derecho de postulación y al deber que tiene el apoderado de probar la calidad de abogado al iniciar la gestión procesal. Esto, en el sentir de los autores, no solo es un deber de los jueces y magistrados, sino que, es un hecho que salvaguarda el perfecto desarrollo del trámite procesal.

Ahora bien, la Corte Suprema de Justicia se equivocó al supeditar la eficacia del acto procesal a la exigencia de la exhibición de la tarjeta profesional del apoderado, máxime cuando este la presentó después de haber sustentado el recurso extraordinario de casación y con anterioridad a la inadmisión del mismo ${ }^{10}$. Por ello, para evitar que los togados incurran en situaciones similares, se recomienda a los abogados realizar la presentación personal del poder, o allegar copia simple de la tarjeta profesional, toda vez que con base en el inciso 5 del artículo 244 del Código General del Proceso, los documentos presentados en copia se presumen auténticos, y por tal razón, el artículo 246 de la misma normatividad les confiere valor probatorio como si fuera un documento original. Esta sugerencia adquiere respaldo legal, y también lógico, en la medida en que, si el Despacho observa la copia de la tarjeta profesional, podrá consultar con el número de esta, la inscripción y los antecedentes disciplinarios del apoderado en el Registro Nacional de Abogados.

10 "Lo más criticable de la decisión de la Corte fue que inadmitió el recurso de casación interpuesto por un abogado que al hacerlo no había exhibido tarjeta profesional quien, no obstante, presentó su tarjeta después de sustentada la casación y antes de que se inadmitiera el recurso, con el argumento de que "no se puede sostener que una vez cumplida la formalidad sus efectos se extiendan hacia el pasado, no sólo porque las actuaciones judiciales no pueden quedar al capricho de las partes, sino porque ello desconocería el principio procesal de la preclusión que precisamente informa el de certeza y seguridad jurídica", lo que constituye un clásico ejemplo de interpretación que sacrifica el derecho sustancial en aras de procesalismos insubstanciales y necios, puesto que si el recurso se presentó en tiempo, que era lo esencial, y el abogado lo era, ha debido darse curso al mismo". (LÓPEZ BLANCO, p. 411 y 412). 
Pintado el estado actual de las cosas, ante un evento en el cual no se realice la presentación personal por parte del apoderado, ni se allegue la copia de la tarjeta profesional, la tesis que se plantea en este artículo, es que el acto procesal que se desencadenó no es ineficaz, sino por el contrario, surtirá los respectivos efectos del proceso; sin embargo, en una etapa o trámite ulterior, será deber del juez o magistrado, comprobar la calidad de abogado solicitándole al apoderado que exhiba su tarjeta profesional (si se está en audiencia o diligencia) o que allegue copia de la misma (si se trata de surtir un trámite escrito). Por ejemplo, si se trata de la presentación de una demanda y el abogado no realizó la presentación personal al poder, mal haría el juez, si profiere auto declarando la inadmisión de la misma indicando que no se cumplió con dicha exigencia jurisprudencial; pues el proceder correcto, si se cumplen los requisitos formales de la demanda, es proferir auto admitiendo el libelo genitor, advirtiendo a su vez, que el reconocimiento de la personería para actuar se realizará cuando se instale la respectiva audiencia, en la cual, el abogado deberá exhibir su tarjeta profesional. En este caso, si la persona se encuentra registrada y autorizada para litigar, se desarrollará la audiencia; de lo contrario, la audiencia no podrá desarrollarse, pero los efectos jurídicos de la presentación de la demanda y del auto admisorio de la misma, se mantendrán incólumes.

\section{El otorgamiento de poderes con ocasión de la Pandemia COVID-19}

En medio del estado de emergencia económica, social y ecológica, declarado en Colombia en el año 2020, se expidió el Decreto Legislativo No. 806 el día 4 de junio de 2020, en cuyo artículo 5, se dispuso que los poderes especiales para cualquier actuación judicial se podrán otorgar a través de documento electrónico, es decir, mediante mensaje de datos, sin que sea necesaria la firma manuscrita o digital; pues para tal efecto, se requiere únicamente la antefirma, indicando nombres y números de documento de identificación (cédula para personas naturales y NIT para personas jurídicas). Con esto, los poderes conferidos con ocasión del COVID-19 se presumirán auténticos y no requerirán de presentación personal o reconocimiento ante notario, juez u oficina judicial de apoyo.

Lo que sí se requiere en estos poderes es la indicación expresa del correo electrónico del apoderado, ya que se debe corroborar que este coincida con la dirección de correo electrónico inscrita en el Registro Nacional de Abogados. De otro lado, los poderes conferidos por las personas inscritas en el registro mercantil deberán ser remitidos desde la dirección de correo electrónico que se inscribió para la recepción de notificaciones judiciales. 
La Corte Constitucional, al declarar la exequibilidad del Decreto 806 de 2020, respecto de los poderes señaló:

[...], el artículo 5 contiene medidas orientadas a identificar al otorgante y garantizar la autenticidad e integridad del mensaje de datos mediante el cual se confiere el poder, en tanto exige que (i) los poderes otorgados por personas inscritas en el registro mercantil envíen el poder desde la dirección inscrita en la respectiva Cámara de Comercio para efectos de notificaciones judiciales, y que (ii) el poderdante indique la dirección del correo electrónico del apoderado al que le confiere el poder, la cual debe coincidir con la que este inscribió en el Registro Nacional de Abogados. En cualquier caso, las medidas que prescribe el artículo son facultativas por lo que, los poderes especiales se pueden seguir otorgando conforme a las normas del CGP. (Corte Constitucional, C-420, 2020)

Ahora bien, analizando la coincidencia del correo electrónico del apoderado, respecto del que aparece en el poder y el que se halla inscrito en el Registro Nacional de Abogados, se debe hacer una advertencia. Dicha coincidencia, no significa que los jueces, magistrados o autoridades administrativas que cumplen jurisdiccionales, deban solicitar a las partes la prueba o soporte que acredite que la dirección de correo electrónico incorporada en el poder coincide con la registrada; por la elemental razón de que no le es permitido al juzgador exigir a las partes el cumplimiento de cargas más allá de las contempladas en la norma, porque ello daría al traste con la garantía constitucional y convencional de acceso a la administración de justicia, aplicando un exceso ritual manifiesto; tal y como lo señaló la Sala de Decisión Civil del Tribunal Superior de Distrito Judicial de Bogotá D.C. (Auto del 30 de septiembre de 2020) al revocar un auto de rechazo de demanda proferido por la Superintendencia de Industria y Comercio.

\section{Terminación del poder}

Si primero se observa el contrato de mandato, este puede llegar a su terminación por causas voluntarias (de la autonomía de las partes) o por causas legales (aquellas dispuestas en el ordenamiento jurídico).

La norma que ilustra las causales de terminación del contrato de mandato es el artículo 2189 del Código Civil; pero, si se hace referencia al apoderamiento judicial, es el artículo 76 del Código General del Proceso el que indica que el poder termina por revocatoria del poderdante o por renuncia del apoderado, y 
a pesar de que la norma no lo establezca, a estas dos formas de terminación del poder se deben agregar: la muerte del apoderado y la inhabilidad sobrevenida e inhabilidad originaria del apoderado judicial.

\section{A. Revocatoria del poder}

Para que la revocatoria como finalización del apoderamiento judicial surta efectos, el poderdante deberá radicar el escrito de revocación ante la secretaría del juzgado, tribunal o de la autoridad administrativa que cumple funciones jurisdiccionales. Esta forma de terminación del poder prevista en los incisos 1 a 3 del artículo 76 del Código General del Proceso, se hace efectiva con el escrito de revocatoria, o también mediante el escrito con el cual se designa a otro apoderado, siempre y cuando ese nuevo poder se otorgue para toda la actuación procesal y no para gestiones determinadas dentro del proceso, porque si se trata de una actuación determinada dentro del proceso, el nuevo apoderado solo podrá intervenir en tal diligencia y el antiguo apoderado en las demás.

Esta revocatoria surte un efecto inmediato, ipso facto, luego de la presentación del memorial que revoca dicho poder. Posteriormente, el juez mediante auto no susceptible de recursos deberá admitir la revocación.

El aspecto que genera inquietud, luego de que opere la revocatoria del poder, sería el relacionado con los honorarios que no se le hayan pagado al apoderado. En esta hipótesis, la norma dispone que dentro de los treinta (30) días siguientes a la notificación de la providencia que admite la revocación del poder, dicho apoderado podrá solicitar ante el juez, que se regulen sus honorarios, para lo cual se abrirá un incidente que se tramitará, con independencia del proceso y de sus etapas sucesivas. Como se trata de un incidente para determinar el monto de los honorarios, el juez deberá tener como medio de prueba el contrato y todos los criterios que sirvan para la fijación de las agencias en derecho.

Puede suceder, que el apoderado no solicite la regulación de honorarios dentro del término señalado, o que los solicite de manera extemporánea; en tales casos, como el término señalado por la ley ha vencido, si el apoderado requiere la regulación y el pago de sus honorarios, deberá presentar demanda laboral ante el juez del trabajo y de la seguridad social.

Si el apoderado a quien le revocaron el poder, solicita el trámite incidental y este se resuelve mediante auto favorable o desfavorable, no se podrá 
controvertir lo decidido en dicha providencia iniciando proceso de carácter laboral, toda vez que esta providencia desde el punto de vista objetivo y subjetivo, una vez ejecutoriada, adquiere plenos efectos de cosa juzgada y esto impide que se nazcan juicios reiterativos.

No sobra resaltar que como se trata de un auto que resuelve un incidente, es un auto apelable si se profiere en la primera instancia de un proceso (Código General del Proceso, num. 5, art. 321).

\section{B. Renuncia al poder}

Cuando se habla de renuncia al poder se hace alusión a la dejación voluntaria del apoderado respecto de la representación judicial del poderdante. Esta renuncia no opera de manera automática, sino, cinco (5) días después de la radicación del memorial de renuncia en el juzgado. Junto con el memorial de renuncia se debe acompañar la comunicación enviada al poderdante informándole esa dimisión. La comunicación enviada al poderdante se puede realizar mediante correo certificado, mediante documento electrónico o mensaje de datos (correo electrónico, chat de WhatsApp, etc.), o también, se le podrá entregar el documento físico contentivo de la renuncia dejando en este una constancia del recibido.

Tratándose de la renuncia al poder, no se podrá presentar incidente de regulación de honorarios. Ello no significa que en caso de que el poderdante deba pagar honorarios al apoderado renunciante, este no pueda pretender su pago; pues en tal hipótesis, el apoderado renunciante podrá demandar al poderdante, ante el juez laboral, probando en tal proceso, que la renuncia tuvo una justa causa.

\section{Muerte del apoderado}

Otra circunstancia de terminación del poder se genera con la muerte del apoderado, pues como el mandato y el apoderamiento están marcados por la característica intuitu personae, esta indica que no son susceptibles de ser transmisibles a sus sucesores o herederos. No se trata de una hipótesis contemplada en el artículo 76 del Código General del Proceso, sino de una hipótesis que encuentra asidero en la lógica del apoderamiento judicial que conlleva a que el poderdante confiera poder a otro abogado titulado e inscrito, de lo contrario, no se podrán desarrollar las etapas del proceso, a menos de que la ley le permita la intervención directa, siempre y cuando se trate de una de las excepciones a la regla general del ius postulandi. 
No ocurre lo mismo con la muerte del mandante o con la extinción de la persona jurídica cuando ya se presentó la respectiva demanda; pues esto nos pone de presente que, en este caso, si se busca la terminación del poder, los herederos o sucesores deberán radicar escrito de revocatoria.

El embrollo se suscita cuando el mandante muere o cuando se extingue la persona jurídica antes de haber radicado la demanda. Ente este caso la pregunta que surge es: ¿El apoderado puede presentar la demanda? La respuesta es que el apoderado sí puede presentar la demanda, toda vez que cuando el poder se otorgó, el poderdante no había muerto, y en el caso de la persona jurídica, esta no se había extinguido. Pese a esto, con posterioridad a la presentación de la demanda, se necesitará la ratificación de los herederos o sucesores.

Tampoco finalizará el poder cuando cesen las funciones del representante de la persona natural o jurídica que lo confirió; pues en este caso, si se desea la terminación del poder, este deberá revocarse por quien corresponda o el apoderado deberá presentar la renuncia.

\section{Inhabilidad sobrevenida del apoderado judicial}

El poder también terminará, cuando el abogado que actúe dentro del proceso sea sancionado por la Sala Disciplinaria del Consejo Seccional de la Judicatura o del Consejo Superior de la Judicatura, prohibiéndole ejercer la profesión de forma temporal o definitiva.

En este caso, es claro que el contrato de mandato y el poder, nacieron y tuvieron efectos en la vida jurídica, sin embargo, la continuidad de estos efectos jurídicos se vio truncada por una sanción disciplinaria que, desde el punto de vista de la representación judicial en el proceso encargado, fue repentina e imprevista.

Inhabilidad sobrevenida no significa que el abogado sancionado esté exonerado del deber profesional de informar tal circunstancia negativa a su cliente, pues este es un deber que se encuentra enmarcado en el lit. b) num. 18 del art. 28 de la Ley 1123 de 2007. Esto lleva a que el abogado sancionado, so pretexto de su inhabilidad sobrevenida, no se pueda desentender del deber profesional que tiene para con el cliente. 


\section{E. Inhabilidad originaria del "apoderado judicial"}

Si se continúa haciendo énfasis en las inhabilidades del apoderado judicial, se detecta lo que he denominado en este artículo: inhabilidad originaria. Esta clase de inhabilidad es cualquier impedimento para litigar que ya reposaba sobre el abogado y que este lo conocía, y, aun así, a sabiendas, de forma dolosa decidió celebrar el contrato de mandato, aceptar el poder otorgado y ejercer la representación judicial. En este supuesto fáctico, no es de recibo señalar que el contrato de mandato y el apoderamiento judicial son válidos; pues el mandato judicial con representación del abogado y consecuente poder, exigen un requisito de capacidad especial ${ }^{11}$ (Código Civil, art. 1504) o sui generis, en el sujeto que obra como apoderado, palabras más palabras menos, se está de frente ante un contrato intuitu personae, y como el abogado no se encontraba habilitado para prestar sus servicios profesionales y ejercer el mandato con la representación, el contrato de mandato adolece de ineficacia por vía de nulidad absoluta (porque no hay capacidad según el art. 1741 del Código Civil).

En caso de haberse iniciado el proceso, dicha inhabilidad originaria del apoderado judicial, tiene una consecuencia procesal, la cual es, que el abogado no podrá continuar representando judicialmente a su poderdante; pero los actos procesales (ejemplo, demanda, contestación de la demanda, etc.) y las etapas del proceso surtidas, no quedan afectadas de nulidad, pues se recuerda que las causales de nulidades procesales, gozan del carácter de taxatividad; luego entonces, para que se estructure una causal de nulidad, esta debe estar expresamente establecida por la ley (pas de nullité sans texte), lo que explica indiscutiblemente, que solo son causales de nulidad procesal las enlistadas en el artículo 133 del Código General del Proceso, en las cuales no figura como causal, haberse desarrollado una actuación por un apoderado judicial inhabilitado. Para consolidar esta posición, ha de agregarse que, el numeral 2 del artículo 159 del Código General del Proceso trata a la inhabilidad, exclusión o suspensión del ejercicio de la profesión de abogado, como causal de interrupción del proceso.

\footnotetext{
11 Para explicar las 'incapacidades especiales HINESTROSA (2015, p. 288) sostiene: “[...] en rigor no se trata de incapacidades, sino de carencias circunstanciales de poder de disposición o legitimación o, más directamente, prohibiciones al sujeto capaz y titular del derecho, de disponer de él en general o frente a determinada persona, por la relación en que se encuentra con ella (incompatibilidad), o de hacerlo a determinado título. Esta posición corresponde a una tendencia antigua a asimilar incapacidad y prohibición [...]".
} 
No se puede señalar que la inhabilidad originaria configure una causal de nulidad procesal, afirmando que quien actuó carecía íntegramente de poder; pues adoptar una posición de esta índole supone consecuencias inesperadas y que la normatividad no contempla; toda vez que, si es el juzgado quien debe enterarse de esta falta de capacidad especial, no podrá manifestar, luego de ejecutadas múltiples actuaciones, que estas quedaron viciadas de nulidad procesal; ya que en ese caso el juzgado estaría decretando una causal de nulidad no establecida ${ }^{12}$, por una irregularidad que desde un inicio debió advertir.

Con todo, no significa que el apoderamiento y la representación judicial ejercida con una inhabilidad originaria no tenga unas consecuencias disciplinarias, sino, por el contrario, se considera una falta cometida a título de dolo, que genera como consecuencia disciplinaria la sanción de expulsión de la profesión. Un actuar de esta naturaleza, vulnera el régimen de incompatibilidades, además de dejar una imagen negativa de la profesión ante la sociedad. Fue esta la razón por la que el Consejo Superior de la Judicatura expidió la Circular PCSJC 19-18 el 9 de julio de 2019, donde se requirió a toda la jurisdicción para que se consulten previamente los antecedentes disciplinarios de los apoderados en cada uno de los despachos, siguiendo lo contemplado en el artículo 39 de la Ley 1123 de 2007; debido a los casos en que varios abogados con sanciones de suspensión, continuaban ejerciendo; y a los cuales, se les impuso la sanción de exclusión de la profesión.

\section{Conclusiones}

El derecho de postulación es aquella prerrogativa que exige, por regla general, que el acceso a la administración de justicia se realice mediante un abogado inscrito respecto del cual no repose ninguna inhabilidad.

El derecho de postulación no es una exigencia de carácter absoluto, sino que, existen excepciones que confirman la regla general, debido a que, en

12 "Tómese por ejemplo el caso de que se ejecutoríe una sentencia en la cual un abogado sea sancionado con cuatro meses de suspensión en el ejercicio profesional y empiece a correr el lapso el 3 de febrero de 2016; ese abogado es apoderado dentro de un proceso ejecutivo en el cual, durante esos cuatro meses y no obstante la suspensión, presentó excepciones e intervino en la práctica de pruebas. Bien claro está que no obstante el desconocimiento de la sanción disciplinaria, en este caso no se ha generado circunstancia que haya deteriorado el ejercicio del derecho de defensa de la parte demandada y, por ende, mal procedería decretar la nulidad sobre la base de la existencia de la causal de interrupción". LÓPEZ BLANCO (p.986 y 987). 
casos específicos, la ley permite y define los casos en los cuales se podrá intervenir en un proceso judicial sin necesidad de abogado.

Si bien el Código General del Proceso establece que para otorgar poder especial se exige la presentación personal del poderdante y no del apoderado; en caso de que el apoderado no realice la presentación personal, sí deberá allegar la copia de la tarjeta profesional con el fin de que el juez pueda constatar su calidad de abogado inscrito en el Registro Nacional de Abogados.

En caso de que el apoderado no le realice presentación personal al poder especial que se le ha otorgado, el acto procesal ejecutado no carecerá de validez; sino que, por el contrario, tendrá absoluta validez y en una etapa o trámite ulterior, se le solicitará al apoderado que exhiba su tarjeta profesional o que allegue copia de esta.

Dentro de las causales de terminación del poder, además de las establecidas por el artículo 76 del Código General del Proceso, como son la revocatoria del poderdante y la renuncia del apoderado; se agregan otras causales como la muerte del apoderado, la "inhabilidad sobrevenida" e "inhabilidad originaria" del apoderado judicial.

\section{Referencias}

Bejarano Guzmán, B. (2019). Procesos declarativos, arbitrales y ejecutivos. Bogotá: Temis.

Bejarano Guzmán, B. (2017). Procesos declarativos, arbitrales y ejecutivos. Bogotá: Temis.

Benavides, J.L. (2016). Código de Procedimiento Administrativo y de lo Contencioso Administrativo, Ley 1437 de 2011, Comentado y concordado (2da ed.). Bogotá: Universidad Externado de Colombia.

Calamandrei, P. (1950). Il processo come giuoco. Padua: Cedam.

Couture, E.J. (2018). Fundamentos del Derecho Procesal Civil. Montevideo - Buenos Aires: $\mathrm{B}$ de $\mathrm{F}$.

Falzea, A. (1960). Capacità (teoría generale). Milano: Giuffrè.

Hinestrosa, F. (2008). La representación. Bogotá: Universidad Externado de Colombia.

Hinestrosa, F. (2015). Tratado de las obligaciones II - De las fuentes de las obligaciones:

El negocio jurídico (Vol. II). Bogotá: Universidad Externado de Colombia.

López Blanco, H.F. (2017). Código General del Proceso - Parte General. Bogotá: Dupré.

Montaña Plata, A. (2010). Fundamentos de Derecho administrativo. Bogotá: Universidad

Externado de Colombia. 
Moreno, C.I. (2018). Acción del consumidor, procedimientos de consumo y sujetos demandados. Análisis comparado entre las legislaciones italiana, española y colombiana. Bogotá: Universidad Externado de Colombia.

Moreno, D.Y. (2014). Derecho constitucional colombiano. Bogotá: Temis.

Nieva Fenoll, J. La cosa juzgada. (2006). Barcelona: Atelier.

Quinche Ramírez, M.F. (2017). La acción de tutela. Bogotá: Temis.

Ruiz Salazar, J.A. (2015). Derecho policivo - Sustantivo y procedimental, Bogotá: Leyer.

Santofimio Gamboa, J.O. (2017). Compendio de Derecho administrativo. Bogotá: Universidad Externado de Colombia.

Sassani, B. (2015). Lineamenti del processo civile italiano. Tutela giurisdizionale, procedimenti di cognizione, cautele, esecuzione. Milano: Giuffrè.

\section{Normatividad:}

Asamblea Nacional Constituyente. (20 de julio de 1991) Constitución Política de Colombia. GC: 116.

Congreso de Colombia. (18 de enero de 2011) Código de Procedimiento Administrativo y de lo Contencioso Administrativo. [Ley 1437 de 2011].DO: 47.956.

Congreso de Colombia. (12 de julio de 2012) Código General del Proceso. [Ley 1564 de 2012]. DO: 48.489.

Congreso de Colombia. (15 de marzo de 1996) Ley Estatutaria de Administración de Justicia. [Ley 270 de 1996]. DO: 42.745.

Congreso de Colombia. (30 de julio de 1997) Por la cual se desarrolla el artículo 87 de la Constitución Política de Colombia. [Ley 393 de 1997]. DO: 43.096.

Congreso de Colombia. (24 de julio de 1997) Por la cual se modifica la Ley $9^{a}$ de 1989, y la Ley $3^{a}$ de 1991 y se dictan otras disposiciones. [Ley 388 de 1997]. DO: 43.091.

Congreso de Colombia. ( 6 de agosto de 1998) Por la cual se desarrolla el artículo 88 de la Constitución Política de Colombia en relación con el ejercicio de las acciones populares y de grupo y se dictan otras disposiciones. [Ley 472 de 1998]. DO: 43.357.

Presidencia de la República. (12 de febrero de 1971) Estatuto del ejercicio de la abogacía. [Decreto 196 de 1971]. DO: 33.255.

Congreso de Colombia. (30 de junio de 2015) Por medio de la cual se regula el Derecho Fundamental de Petición y se sustituye un título del Código de Procedimiento Administrativo y de lo Contencioso Administrativo. [Ley 1755 de 2015]. DO: 49.559.

Congreso de Colombia. (28 de junio de 2018) Por la cual se dictan disposiciones relacionadas con el ejercicio de la profesión de abogado. [Ley 1905 de 2018].DO: 50.638.

Congreso de Colombia (14 de diciembre de 1982) Por la cual se conceden facultades extraordinarias al Presidente de la República para reformar el Código Contencioso Administrativo). [Ley 58 de 1982]. DO: 36163.

Congreso de Colombia (24 de enero de 2001) Por la cual se modifican normas relativas a la conciliación y se dictan otras disposiciones. [Ley 640 de 2001]. DO: 44.303.

Presidencia de la República (24 de junio de 1948) Código Procesal del Trabajo y de la Seguridad Social. [Decreto-Ley 2158 de 1948]. DO: 44.640.

Congreso de Colombia (21 de diciembre de 1945) Por la cual se desarrolla el artículo 40 de la Constitución Nacional, sobre el ejercicio de la Abogacía. [Ley 69 de 1945]. DO: 26.019 . 
Congreso de Colombia (29 de julio de 2016) Por la cual se expide el Código Nacional de Seguridad y Convivencia ciudadana. [Ley 1801 de 2016]. DO: 49.949.

Congreso de Colombia (12 de junio de 2000) Por la cual se modifican los artículos 30 y 9 del Decreto 196 de 1971. [Ley 583 de 2000]. DO: 44.042.

Congreso de Colombia (26 de mayo de 1873) Código Civil. [Ley 84 de 1873]. DO: 2.867. Presidencia de la República (4 de junio de 2020) Por la cual se adoptan medidas para implementar las tecnologías de la información y las comunicaciones en las actuaciones judiciales, agilizar los procesos judiciales y flexibilizar la atención a los usuarios del servicio de justicia, en el marco del Estado de Emergencia Económica, Social y Ecológica. [Decreto Legislativo 806 de 2020]. DO: 51.335.

Congreso de Colombia (22 de enero de 2007) Código Disciplinario del Abogado. [Ley 1123 de 2007]. DO: 46.519.

\section{Decisiones judiciales:}

Corte Constitucional. (25 de enero de 2006) Sentencia T- 020. [M.P.: Rodrigo Escobar].

Corte Constitucional. (28 de abril de 2006) Sentencia T-328. [M.P.: Marco Gerardo Monroy]

Corte Constitucional. (6 de junio de 2006) Sentencia T-451. [M.P.: Jaime Araújo].

Corte Constitucional. (28 de marzo de 2019) Sentencia C-138. [M.P.: Alejandro Linares].

Corte Constitucional. (29 de septiembre de 2004) Sentencia C-932. [M.P.: Jaime Córdoba].

Corte Constitucional. (2 de marzo de 2018) Sentencia T-077. [M.P.: Antonio José Lizarazo].

Corte Constitucional. (1 de noviembre de 2011) Sentencia C-818. [M.P.: Jorge Ignacio Pretelt].

Corte Constitucional. (7 de febrero de 2011) Sentencia C-143. [M.P.: José Hernández].

Corte Constitucional. (24 de septiembre de 2020) Sentencia C-420. [M.P. (E) Richard Ramírez].

Consejo de Estado, Sección Tercera. (22 de abril de 2013.) Auto. [C.P.: Hernán Andrade].

Corte Suprema de Justicia, Sala de Casación Civil. (31 de octubre de 2018) Auto 2004 00042. AC-4741-2018. [M.P.: Margarita Cabello].

Corte Suprema de Justicia, Sala de Casación Civil. (24 de febrero de 2021) Sentencia11001-22-03-000-2020-01925-01 [M.P.: Francisco Ternera].

Corte Suprema de Justicia, Sala de Casación Civil. (21 de abril de 1982) Sentencia 893, M.P.: [Manuel Gaona Cruz].

Corte Suprema de Justicia, Sala de Casación Civil. (3 de junio de 1999) Auto 7657 [M.P.: Jose Fernando Ramírez].

Consejo Superior de la Judicatura. (9 de julio de 2019) Circular PCSJC 19-18.

Tribunal Superior de Bogotá D.C., Sala de Decisión Civil. (30 de septiembre de 2020) Auto 001-2020-12423-01. [M.P.: Adriana Saavedra]. 